\title{
SIMULTANEOUS BILATERAL OCULAR HAEMORRHAGES IN SCURVY*
}

\author{
BY \\ C. A. L. PALMER $\dagger$ \\ Department of Ophthalmology, University of Manchester
}

THE occurrence of haemorrhages in and around the globe in cases of scurvy is well-recognized. Effusions of blood into the conjunctiva, lids, and orbit have been described by Stephenson (1915) and Blake (1921). Duke-Elder (1952) stated that adults are rarely affected, the effusions occurring almost invariably in children. A case of simultaneous bilateral ocular haemorrhage in an adult is reported below.

\section{Case Report}

An old-age pensioner aged 69 years was referred on March 29, 1962, complaining that 4 days before, he had awakened to find that he had two "black eyes". There was no history of trauma, but he admitted to a bad cough.

Examination.-There were bilateral ecchymoses of the eyelids and subconjunctival haemorrhages (Fig. 1). The ocular movements were full and there was no proptosis. The visual acuity was $6 / 12$ in the right eye, and 6/9 in the left; the fundi were normal and there were no retinal haemorrhages.

Blood Count.-Haemoglobin: $10 \cdot 4 \mathrm{~g}$. per cent. Red blood cells: 3.14 million/mm. ${ }^{3}$. Colour index: $1 \cdot 11$. White blood cells: $4 \cdot 850 / \mathrm{mm}^{3}$. Differential count: normal.

Diagnosis.-He was referred to the Department of Clinical Haematology, University of Manchester. When he was asked about his diet, it became clear that he was undernourished; his wife did not cook for him and he had to fend for himself. He lived principally on pies, meats, and tea, and took no fruit or green vegetables.

In addition to the ocular haemorrhages, he appeared clinically anaemic and the gums were moderately inflamed. The left calf was swollen, tense and red; findings which were

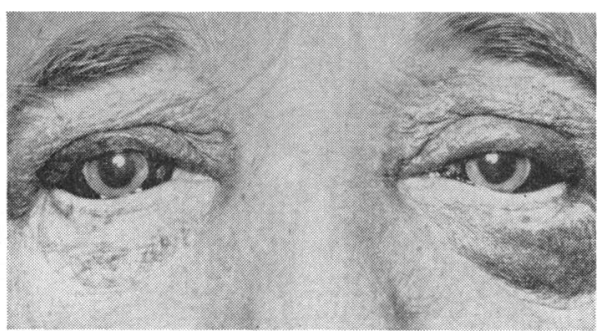

FIG. 1.-Appearance of patient at first attendance.

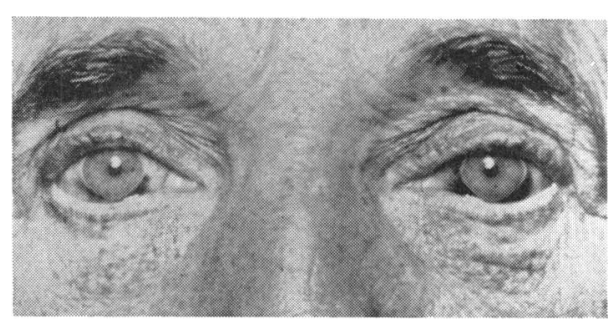

Fig. 2.-Appearance of patient one month later.

* Received for publication January 9, 1963.

† Present address: Royal Infirmary, Sheffield. 
attributed to a haematoma. The vitamin $\mathrm{C}$ saturation test showed that he was moderately deficient; plasma ascorbic acid was $0.27 \mathrm{mg}$. per cent. (normal 1 to $2 \mathrm{mg}$. per cent.). A radiological skeletal survey showed no evidence of subperiosteal haemorrhages.

Progress.-Fig. 2, taken one month after his first attendance and just before the start of treatment, shows considerable resolution of the haemorrhages.

Ascorbic acid $750 \mathrm{mg}$. daily was prescribed, and rapid improvement in his general condition took place. When he was seen again on April 27, the haemorrhages had almost cleared.

\section{Comment}

The haemorrhagic manifestations of scurvy are said to be caused by the loss of colloidal cement substance in the capillary endothelium; there is no defect in the blood-clotting mechanism. The anaemia which co-exists in some cases of scurvy is not due to iron deficiency, but stems from a depression of erythropoiesis (Israëls, 1943).

Proptosis was not found in this case, and would not have been expected, since this manifestation of scurvy is confined to infants under 2 years old (Dunnington, 1932), and is due to extravasation between the orbital roof and the periosteum.

The simultaneous appearance of bilateral haemorrhages requires explanation; the mechanism is not immediately obvious. However, this patient suffered from congestive cardiac failure in addition to scurvy; it may be that some sudden stress, such as a cough, precipitated the haemorrhages.

I am grateful to Mr. O. M. Duthie and Mr. R. Dalgleish for permission to publish this case report, and to Dr. M. C. G. Israëls, Director, Department of Clinical Haematology, University of Manchester, for the haematological details and for helpful advice. The illustrations were prepared by the Department of Medical Illustration, Manchester Royal Infirmary (Dr. Robert Ollerenshaw).

\section{REFERENCES}

BlaKe, E. M. (1921). Amer. J. Ophthal., 4, 736.

Duke-ElDER, S. (1952). "Text-book of Ophthalmology", vol. 5, p. 5393. Kimpton, London. Dunnington, J. H. (1931). Arch. Ophthal. (Chicago), 6, 731.

ISRAËLS, M. C. G. (1943). Lancet, 1, 170.

STEPHENSON, S. (1915). Ophthalmoscope, 13, 132. 